\title{
Piracy on the internet: Accommodate it or fight it? A dynamic approach
}

Citation for published version (APA):

Herings, P. J-J., Peeters, R., \& Yang, M. (2018). Piracy on the internet: Accommodate it or fight it? A dynamic approach. European Journal of Operational Research, 266(1), 328-339.

https://doi.org/10.1016/j.ejor.2017.09.011

Document status and date:

Published: 01/04/2018

DOI:

10.1016/j.ejor.2017.09.011

Document Version:

Publisher's PDF, also known as Version of record

Document license:

Taverne

Please check the document version of this publication:

- A submitted manuscript is the version of the article upon submission and before peer-review. There can be important differences between the submitted version and the official published version of record.

People interested in the research are advised to contact the author for the final version of the publication, or visit the DOI to the publisher's website.

- The final author version and the galley proof are versions of the publication after peer review.

- The final published version features the final layout of the paper including the volume, issue and page numbers.

Link to publication

\footnotetext{
General rights rights.

- You may freely distribute the URL identifying the publication in the public portal. please follow below link for the End User Agreement:

www.umlib.nl/taverne-license

Take down policy

If you believe that this document breaches copyright please contact us at:

repository@maastrichtuniversity.nl

providing details and we will investigate your claim.
}

Copyright and moral rights for the publications made accessible in the public portal are retained by the authors and/or other copyright owners and it is a condition of accessing publications that users recognise and abide by the legal requirements associated with these

- Users may download and print one copy of any publication from the public portal for the purpose of private study or research.

- You may not further distribute the material or use it for any profit-making activity or commercial gain

If the publication is distributed under the terms of Article $25 \mathrm{fa}$ of the Dutch Copyright Act, indicated by the "Taverne" license above, 


\title{
Piracy on the Internet: Accommodate it or fight it? A dynamic approach
}

\author{
P. Jean-Jacques Herings ${ }^{a, *}$, Ronald Peeters ${ }^{a}$, Michael S. Yang ${ }^{b}$ \\ a Department of Economics, Maastricht University, P.O. Box 616, Maastricht 6200 MD, The Netherlands \\ ${ }^{\mathrm{b}}$ Frontier Economics, 71 High Holborn, London WC1V 6DA, United Kingdom
}

\section{A R T I C L E I N F O}

\section{Article history:}

Received 30 June 2016

Accepted 10 September 2017

Available online 18 September 2017

\section{Keywords:}

Game theory

Economics

Markov processes

OR in societal problem analysis

Pricing,

\begin{abstract}
A B S T R A C T
This paper uses a dynamic stochastic model to solve for the optimal pricing policy of music recordings in the presence of P2P file-sharing networks eroding their sales. We employ a policy iteration algorithm on a discretized state space to numerically compute the optimal pricing policy. The realistically calibrated model reflects the real-world figures we observe and provides estimates of the optimal pricing policy as well as comparative statics figures. The pricing policy is such that, for a given P2P network size, prices are increasing in the number of buyers of the product and, for a given number of buyers of the product, prices are non-monotonic in the P2P network size. Surprisingly, in the presence of P2P networks, increases in production costs and decreases in the valuation of the product increase the consumer and total surplus. A higher valuation of the product leads to a lower steady state price. Increased switching costs have a negative effect on prices and profits, so the long term incentive to attract new consumers dominates the short term incentive to harvest loyal consumers. The full enforcement of intellectual property rights has adverse effect on both consumer surplus and total welfare.
\end{abstract}

(c) 2017 Elsevier B.V. All rights reserved.

\section{Introduction}

Ever since Napster emerged in 1999, P2P (peer-to-peer) filesharing networks have been the center of piracy on the Internet. We have seen different generations of P2P technology come and go thanks to the legal pursuits launched by various authorities and interest groups alike and the development of new technologies that help evade them. The content providers try to defend their creations from free riding; whilst the online communities try to preserve the true free and sharing spirit of the Internet. The battle goes on and on, but we cannot ignore the impact it has had on the markets of information goods, particularly the music industry.

Numerous studies, especially empirical ones, over the years have tried to explain the relationship between the decline in music sales and the rise of P2P networks. Blackburn (2004), Liebowitz (2004), Rob and Waldfogel (2006), and Zentner (2006) find that downloading (via P2P file-sharing networks) is at least partially responsible for the decrease in music sales. Liebowitz (2006) concludes that file-sharing has clearly brought significant harm to

\footnotetext{
* Corresponding author.

E-mail addresses: P.Herings@maastrichtuniversity.nl (P.J.-J. Herings), R.Peeters@maastrichtuniversity.nl_ (R. Peeters), michael.yang@frontiereconomics.com (M.S. Yang).
}

the recording industry. In contrast, Oberholzer-Gee and Strumpf (2007) and Peitz and Waelbroeck (2004) find little robust evidence that P2P has caused the decrease in music sales.

The classical theoretical literature on piracy and network effects include, among others, Economides (1996), Katz and Shapiro (1985), Katz and Shapiro (1986), Johnson (1985), and Takeyama (1994). Recent papers that study P2P in specific include, among others, Gayer and Shy (2003), Sundararajan (2004), Bae and Choi (2006), Peitz and Waelbroeck (2006), Herings, Peeters, and Yang (2010), Dewan and Ramaprasad (2014), Chang and Walter (2015), and Zhang (2017).

Gayer and Shy (2003) show how publishers of digitally-stored products, including music, can utilize P2P to enhance sales of their product sold in the store or online. This result is mainly attributable to the positive consumptive externality ingredient in their model. Sundararajan (2004) addresses the issue of optimal digital rights management systems in markets with digital piracy. Using a sample comprising 5864 albums from 634 artists sold in the years 1992-2011, Zhang (2017) shows that the effect of digital rights management on sales highly depends on the album's age and position on the sales distribution, with new popular albums suffering and older niche or unpopular albums benefitting from a removal of digital rights management. Peitz and Waelbroeck (2006) show that under sufficient taste heterogeneity and product diversity, the positive effect of downloading on 
sales due to sampling may compensate the direct negative effect. This result is mainly driven by the information asymmetry between the buyers and the sellers of the product, and downloaded files can help buyers identify their favorite products more easily and hence encourage sales. A recent empirical investigation on the impacts of social media on music sales is provided by Dewan and Ramaprasad (2014). Herings et al. (2010) analyzes the different market structures that may form. The paper concludes that, depending on different circumstances, the firm will employ pricing strategies either to deter the entry of a network or to accommodate it. Moreover, music industry profits decrease when the generic cost factor of downloading declines, i.e. when the society is more downloader-friendly, whereas total welfare increases. Chang and Walter (2015) extends the analysis of Herings et al. (2010) by making the investment by the P2P network to improve the quality and accessibility of the information goods an endogenous variable.

All the theoretical studies on this subject have been of a static nature. This implies that in the presence of demand side externalities there may be multiple equilibria due to coordination issues related to network size. The literature has always focused on the maximally achievable network size. However, these models lack insights on how such networks actually form, step by step, from zero to a steady-state network size; how the firm prices strategically to compete with the network every step of the way; and how society is affected during the process. This makes it impossible for such models to address the dynamic development of the P2P network as we see it in reality.

Only a dynamic model can bring such insights, which is what this paper is designed to achieve. Dynamic stochastic models with network externalities have been recently studied in the industrial organization literature, mainly using numerical methods. Examples are Markovich (2008) and Markovich and Moenius (2009) which study the dynamics caused by the iterations between hardware and software; Jenkins, Liu, Matzkin, and Mc (2004) studies a stylized version of the browser war between Netscape and Microsoft, where the entrant may have "grabbed" market shares from the incumbent and thereby tipped the market; Chen, Doraszelski, and Harrington (2009) studies competing firms' incentives to make their products compatible and the possible effects that may prevent market dominance; and Arie and Grieco (2014) investigate the effect of switching costs on market dominance and equilibrium prices. A framework for numerically analyzing dynamic interactions in imperfectly competitive industries is proposed by Doraszelski and Pakes (2007), which provides an excellent summary of the main approach for models of this kind. Doraszelski and Satterthwaite (2010) show how this class of models can be formulated to ensure the existence of a computationally tractable Markov-perfect equilibrium.

In this paper, we use a dynamic model to solve for the optimal pricing policy of a firm that releases music products while being exposed to a competing P2P file-sharing network on the Internet. In the model, there is a firm who sets the price of its music product every period and a continuum of consumers who decide whether to make a legal purchase of the music product, to download the music from P2P, or to not acquire the music at all. The timing involves discrete periods with infinite horizon. The firm is forward looking and strives to maximize the present value of all future profits by choosing a state-dependent pricing policy; the state being the shares of legal sales, the P2P network, and the unserved market. The consumers make one of the three choices in order to maximize their utility while taking into account the price and the state. Consumers are ex ante identical, but receive random utility shocks prior to their purchasing decision every period anew. Switching costs are imposed on the consumers who switch to a product, from previously consuming the other product or not con- suming at all. The firm's optimal pricing policy is derived numerically and provides insight in the market share dynamics.

Other work on the optimal pricing policy of a firm selling information goods while dealing with piracy has been done by Khouja and Smith (2007) and Waters (2015). In these papers, the emphasis is on the sales of a single product with a limited life time and the use of skimming strategies to maximize the firm's profit by first selling the legal product to consumers with high valuations for it. Piracy is modeled by assuming that some multiple of legal sales will lead to illegal sales. This reduces demand for the legal product, since consumers buy only once. In our model, the demand for the legal product renews in every period and the extent of piracy is endogenously determined as a consequence of consumers' choices.

To illustrate our model, we have calibrated its parameters to real-world data. To do so, we use data from the period between 1999 and 2007. The year 1999 has been chosen as the starting point of appearance of illegal P2P networks since, as argued in Waldfogel (2010), in 1999 the appearance of Napster made it convenient for consumers to download music illegally from P2P networks. According to the RIAA (2009) year-end report, the year 2007 is the last year in which legal downloads and streaming of music were not very significant yet and the main revenues for music companies were coming from physical CD sales. Although our model is by no means restricted to the legal music sales taking the form of $\mathrm{CDs}$, it would be unreasonable to assume that the model's parameter values are the same before and after 2007.

Although we calibrate the model to data coming from the period 1999-2007, it is by no means the case that new technological developments like legal downloads, streaming services, or Internet radio have eliminated piracy after 2007. For instance, the report (MUSO, 2017) of the content protection company MUSO recently revealed data showing that during 2016, 191 billion visits to piracy websites were made globally, out of which 34.2 billion were visits to music piracy sites. This represents a modest decline of $6 \%$ compared to music piracy in 2015. Although by now web streaming sites are the most popular method for consuming illegal content, public torrent sites are still the second most popular method for doing so. As IFPI (2017) puts it: "Protecting music from being illegally distributed - and therefore undermining the recovering legitimate music market - remains a key priority for the industry."

Switching costs turn out to be quite important to match the development of the real-world data during 1999-2007. We use calibration to estimate the value of switching costs to be equal to $\$ 12$. We think of a significant part of these switching costs as being mental costs of switching and time needed to evaluate a change in behavior. Indeed, there is a substantial empirical literature suggesting a status quo bias. Values for switching costs as found in the empirical literature for a wide spectrum of applications are well in line with the value found for our application. To give some examples, Shy (2002) examines the Israeli mobile phone industry and finds switching costs equal to $\$ 269$ on average. In the Finnish demand-deposit banking industry, he finds average switching costs equal to $\$ 331$. Shcherbakov (2009) estimates switching costs in the paid TV industry to be $\$ 109$ for cable subscribers and $\$ 186$ for satellite subscribers. Just to give an example from a market that does not have any kind of technologically determined lock-in effects, Shum (2004) estimates the average switching costs for breakfast cereals to be $\$ 4.33$. For a nice survey of recent empirical work that estimates the size of switching costs in a variety of markets, we refer to Arie and Grieco (2014).

An interesting point of our approach is that we can study how networks develop in a dynamic process without having to make any assumptions on consumer coordination as in the conventional 
static models of network economics. We can also observe exactly how the firm sets its price conditioned on its market share and that of the network. While for given network size the price the firm sets is generally increasing in its market share, for given market share the price behaves non-monotonically in the network size. Sometimes the firm sets the price very low in order to win vital market shares to fight against the P2P network, while other times it accommodates the network by setting a high price to reap the profit from its own installed customer base.

We use the model to compute the changes in profits, consumer surplus and total welfare. The firm's profit decreases steadily over the years, resulting in a loss of $\$ 1.0$ billion in annual profits by the year 2007. However, consumer surplus increases by $\$ 122.0$ billion per year in the same period, resulting in a huge increase in the annual total surplus generated by the P2P downloads. Next we turn to the comparative statics at the steady state resulting from the firm's optimal pricing policy after the appearance of P2P. On the one hand, we find the standard results that the firm's sales quantities and profits increase in the consumer's valuation of its product, decrease in its production costs, and decrease in the consumer's valuation of the illegal download. At the same time, we find that higher production costs increase consumer and total surplus, which is caused by the positive downloading externalities related to the P2P network. For exactly the same reason, we find that a higher valuation of the firm's product has a negative effect on consumer and total surplus. Higher switching costs lead to lower prices and profits, but also less consumer surplus, both because of the higher costs of switching and the weaker development of the P2P network.

One of our most important findings is that consumer surplus and total welfare is negatively related to the generic cost factor of downloading. This result coincides with the findings from papers such as Rob and Waldfogel (2006) and Herings et al. (2010) in the sense that the existence of P2P actually enhances total welfare. This implies that by making file-sharing more difficult for the consumers, the government is effectively curbing the society from enjoying a high welfare level.

Many of the counterintuitive comparative statics results are caused by the positive downloading externalities as generated by the P2P network. We also analyze a model where downloading costs are constant and there are no such externalities. We argue that such an alternative model is not compatible with the observed data.

In our model, the quality of the legal product is not affected by the existence of P2P networks. As long as we consider a limited time period, say from 1999 to 2007, we believe such an assumption is justified. But for the long run, it clearly may not be so, and it would be interesting to extend our model to one with endogenous quality choices. It is commonly believed that piracy leads to lower incentives to invest in innovation and thereby to lowerquality products. Nevertheless, Lahiri and Dey (2013) find many practical examples that contradict this claim. Moreover, they develop a model of the firm's quality decision problem in the presence of piracy. It is found that in certain situations lower enforcement of property rights increases the monopolist's incentive to invest in quality. Similarly, in the closely related literature on counterfeits, Qian (2014) discusses the advertising and substitution effects of counterfeits, and finds a positive effect of counterfeits for high-end products and a negative effect for low-end products.

The remainder of the paper is organized as follows. In Section 2 the dynamic model is described in detail. Next, Section 3 explains how the numerical computations are conducted. In Section 4 the model is calibrated and the parameter values for the benchmark scenarios are set. The model outcomes and predictions are then presented in Section 5, and comparative statics are analyzed in Section 6. Section 7 concludes.

\section{The model}

Each period, music products are being offered by a firm, but can also be illegally downloaded for free via a P2P network. Buying the product from the firm means acquiring a legal product, either in physical or digital form, at a store at a given price. Our model does not distinguish between both forms as long as the sales are legal. For an in depth analysis of the firm's choice between selling the product in physical form, digital form, or both, we refer the reader to Khouja and Wang (2010). On the contrary, downloading via P2P networks is an illegal activity which does not require money, but only effort.

A continuum of consumers decides whether to legally acquire music at the store $(S)$, to download it via P2P networks $(N)$, or not to acquire it at all $(E)$. A consumer's decision in one period determines her type in the subsequent period. That is, at each period, depending on the decision in the previous period, a consumer is of one of the three possible types: $\theta_{S}$ (store), $\theta_{N}$ (network), or $\theta_{E}$ (empty). Note here that while our model does not allow consumers to multi-home within a given period, consumers can switch between platforms throughout time. The state at a certain period is defined as the distribution of consumers over types. Setting the total mass of consumers equal to 1 , the state space is given by

$\Omega=\left\{(s, n, e) \in \mathbb{R}_{+}^{3} \mid s+n+e=1\right\}$,

where $s, n$, and $e$ represent the share of consumers of type $\theta_{S}, \theta_{N}$, and $\theta_{E}$, respectively. A typical state in $\Omega$ is denoted by $\omega$.

Every period, given the current state $\omega$, the firm sets a price for its product in the store $p(\omega)$. This generates an immediate profit of

$\pi(\omega, p(\omega))=(p(\omega)-\mu) \cdot d(\omega, p(\omega))$,

where $\mu$ represents the cost of producing one unit and $d(\omega, p(\omega))$ represents the resulting demand, which equals the number of consumers choosing to buy the album in store given the current state $\omega$ and price $p(\omega)$. Hence, in the next period the process will be in a state with $d(\omega, p(\omega))$ consumers of type $\theta_{S}$. When designing an optimal pricing policy, the firm realizes that the price chosen in the current state does not only affect the immediate profit, but also the state transitions and thus potential profits in the future. We assume the firm to be rational and farsighted. That is, in any period, it sets the price as to maximize the present value of the stream of profits discounted by a factor of $\delta$ each period.

Given the current market state $\omega$ and the firm's price at this state $p(\omega)$, the state transition is completely specified by the consumers' decisions. We assume consumers to maximize their utility in the current state. In her decision, a consumer takes into account the price at the store, the downloading costs, and the switching costs $\tau$. The purpose of the switching costs $\tau$ in the model is to promote consumer loyalties to the platforms, reflecting a possible lock-in effect.

In our model the downloading cost is negatively related to the network size and the switching cost is incurred only when a consumer acquires the product while changing type. Hence, a consumer's decision is determined by her type, the price at the store, and the network size. Given the current state $\omega=(s, n, e)$, the utility of a consumer of type $\theta \in\left\{\theta_{S}, \theta_{N}, \theta_{E}\right\}$ who chooses an alternative $x \in\{S, N, E\}$ is denoted by $U(\theta, x)$ and is defined by

$$
\begin{aligned}
& U\left(\theta_{S}, x\right) \\
& =\left\{\begin{array}{lll}
\beta-p(\omega) & +\varepsilon_{S} & \text { if } x=S \text { (buy in store) } \\
\gamma-c(n)-\tau & +\varepsilon_{N} & \text { if } x=N \text { (download from network) } \\
0 & +\varepsilon_{E} & \text { if } x=E \text { (no acquisition at all) }
\end{array}\right.
\end{aligned}
$$




$$
\begin{aligned}
& U\left(\theta_{N}, x\right) \\
& =\left\{\begin{array}{lll}
\beta-p(\omega)-\tau & +\varepsilon_{S} & \text { if } x=S \text { (buy in store) } \\
\gamma-c(n) & +\varepsilon_{N} & \text { if } x=N \text { (download from network) } \\
0 & +\varepsilon_{E} & \text { if } x=E \text { (no acquisition at all) }
\end{array}\right. \\
& U\left(\theta_{E}, x\right) \\
& =\left\{\begin{array}{lll}
\beta-p(\omega)-\tau & +\varepsilon_{S} & \text { if } x=S \text { (buy in store) } \\
\gamma-c(n)-\tau & +\varepsilon_{N} & \text { if } x=N \text { (download from network) } \\
0 & +\varepsilon_{E} & \text { if } x=E \text { (no acquisition at all). }
\end{array}\right.
\end{aligned}
$$

The parameters $\beta>0$ and $\gamma>0$ represent the basic utility of the legal product and the illegally downloaded form, respectively. The costs of downloading when the resulting network is of size $n \in[0$, 1] are represented by $c(n)$. A natural shape of this cost function is for it to be decreasing in the network size at a diminishing rate. This is due to the fact that the more users are sharing this file, the easier it is to acquire it from the P2P network. ${ }^{1}$ In our model we implement the following convex decreasing cost function:

$$
c(n)=\frac{\sigma}{\rho+n}, \quad n \in[0,1] .
$$

Here $\sigma>0$ represents the generic cost factor of downloading, incorporating a collection of factors that may affect downloading costs; for instance, population computer literacy, the availability of broadband Internet infrastructure, and most importantly, the degree of legal enforcement of intellectual property rights. The parameter $\rho>0$ influences the curvature of the cost function. The smaller $\rho$ is, the steeper $c(n)$ is around the region where $n$ is close to 0 . Moreover, a positive $\rho$ guarantees a finite price at a zero network, capturing the idea that initial seeding peers are always around, and giving opportunity for the network to further develop. Note that $\rho$ and $\sigma$ are identical for all consumers and are independent of the network size.

Finally, the terms $\varepsilon_{S}, \varepsilon_{N}$, and $\varepsilon_{E}$ are random terms leading to heterogeneous consumer behavior. These terms capture the additional (possibly negative) utility that a consumer obtains on top of the basic utility of the physical, the illegally downloaded form, and the outside options, respectively. We assume that these terms are independently drawn according to a Gumbel extreme value distribution with location parameter 0 and scale parameter $\lambda>0$ for each consumer and each of the three alternative choices every period anew. The scale parameter $\lambda$ is inversely related to the level of heterogeneity among consumers' preferences.

Our specification of consumers' choice behavior corresponds to the well-known logit model, the most widely used discrete choice model in applied work. Luce (1959) provides axiomatic foundations for the logit model and shows that the logit model follows from the axiom of independence of irrelevant alternatives. This axiom states that the ratio of the probabilities of selecting one alternative over another is not affected by the presence of other alternatives. As argued by Train (2003), choice probabilities that exhibit independence of irrelevant alternatives provide an accurate representation of reality in many settings.

In our setup, the explicit function forms of the logit model are as follows. Given the current state $\omega$ and the store's price at this state $p(\omega)$, the probability that a consumer with type $\theta$ is of type $\theta_{x}$ next period is then given by:

$$
\begin{aligned}
& q\left(\theta_{x} \mid \theta\right)[\omega, p(\omega)] \\
& =\frac{\exp (\lambda U(\theta, x))}{\exp (\lambda U(\theta, S))+\exp (\lambda U(\theta, N))+\exp (\lambda U(\theta, E))},
\end{aligned}
$$

for $\theta \in\left\{\theta_{S}, \theta_{N}, \theta_{E}\right\}$ and $x \in\{S, N, E\}$. Hence, from state $\omega=(s, n, e)$ with price $p(\omega)$, the process resumes in state $\omega^{\prime}=\left(s^{\prime}, n^{\prime}, e^{\prime}\right)$ next

\footnotetext{
${ }^{1}$ Notice that unlike local area networks, contemporary P2P networks are less prone to network congestions.
}

period, where

$s^{\prime}=s \cdot q\left(\theta_{S} \mid \theta_{S}\right) n \cdot q\left(\theta_{S} \mid \theta_{N}\right) e \cdot q\left(\theta_{S} \mid \theta_{E}\right)=d(\omega, p(\omega))$,

$n^{\prime}=s \cdot q\left(\theta_{N} \mid \theta_{S}\right) n \cdot q\left(\theta_{N} \mid \theta_{N}\right) e \cdot q\left(\theta_{N} \mid \theta_{E}\right)$,

$e^{\prime}=s \cdot q\left(\theta_{E} \mid \theta_{S}\right) n \cdot q\left(\theta_{E} \mid \theta_{N}\right) e \cdot q\left(\theta_{E} \mid \theta_{E}\right)$.

We denote this process of state transitions by $Q: \Omega \times \mathbf{R}_{+} \rightarrow \Omega$.

The firm maximizes the present value of all future profits by implementing the pricing policy $p: \Omega \rightarrow \mathbf{R}_{+}$, which for all $\omega \in \Omega$ maximizes the value of

$V(\omega, p)=\pi(\omega, p(\omega))+\delta \cdot V(Q(\omega, p(\omega)), p)$,

the Bellman equation for the firm's profit maximization problem.

The firm's search for the optimal pricing policy constitutes a Markov decision problem. To solve this problem, we turn to numerical methods. More precisely, we discretize the state space and apply a policy iteration algorithm to find the optimal pricing policy. Details on the numerical method are further explained in Section 3 . The process of state transitions that is induced by this pricing policy provides insight in the implied market share dynamics. In our simulations, presented in later sections, the state transition process leads to a unique invariant distribution. The set of states with positive probabilities in the invariant distribution is called the absorbing set. We refer to it as the long-run steady state or just the steady state in the non-technical parts of the paper.

\section{Numerical method}

In this section, we explain how the model described in Section 2 is solved numerically. Firstly, we discretize the state space and adapt the firm's problem accordingly. Next, we apply the policy iteration algorithm ${ }^{2}$ on the discretized state space. Finally, we apply a bracketing algorith ${ }^{3}$ to determine improvements in each state of the pricing policy.

\subsection{Discretization}

wGiven a natural number $k \geq 1$, we define the discretized state space by

$\widehat{\Omega}=\left\{(\widehat{s}, \widehat{n}, \widehat{e}) \in K^{3} \mid \widehat{s}+\widehat{n}+\widehat{e}=1\right\}$,

where $K=\{0,1 / k, 2 / k, \ldots, 1\}$. Fig. 1 illustrates the state space and the discretized state space graphically for $k=4$. The large triangle represents the state space. The corner points of this triangle represent the extreme states with full consumer mass at either Store, Network, or Empty. Each given point in the large triangle can be written uniquely as a convex combination of the three corner points and the weight put on a corner point is equal to the probability mass the given point attaches to the corresponding platform. The triangulation of the triangle represents the discretized state space. The vertices are precisely the states in $\widehat{\Omega}$.

Next, we define a transition mapping $\widehat{Q}: \widehat{\Omega} \times \mathbf{R}_{+} \rightarrow \mathcal{P}(\widehat{\Omega})$ on this discretized state space, where $\mathcal{P}(\widehat{\Omega})$ denotes the set of probability distributions over $\widehat{\Omega}$. Given current state $\widehat{\omega} \in \widehat{\Omega}$ and pricing policy $p: \widehat{\Omega} \rightarrow \mathbf{R}_{+}$the process resumes in state $\omega^{\prime}=Q(\widehat{\omega}, p(\widehat{\omega}))$. Typically the new state $\omega^{\prime}=\left(s^{\prime}, n^{\prime}, e^{\prime}\right)$ is not an element of $\widehat{\Omega}$. In such a case we allocate probabilities to the nearest states in $\widehat{\Omega}$ such that the expected value of the state is equal to $\omega^{\prime}$. The probability assigned to a state $\widehat{\omega}^{\prime} \in \widehat{\Omega}$ by the probability distribution $\widehat{Q}(\widehat{\omega}, p(\widehat{\omega}))$ is denoted by $\widehat{Q}\left(\widehat{\omega}^{\prime} \mid \widehat{\omega}, p(\widehat{\omega})\right)$.

In order to provide a precise formulation of the discretized transition mapping, it is convenient to define for a state $\omega^{\prime} \in \Omega$ the

\footnotetext{
2 See Howard (1960), Blackwell (1965), see also Judd (1998, p. 416).

${ }^{3}$ Cf. Judd (1998).
} 


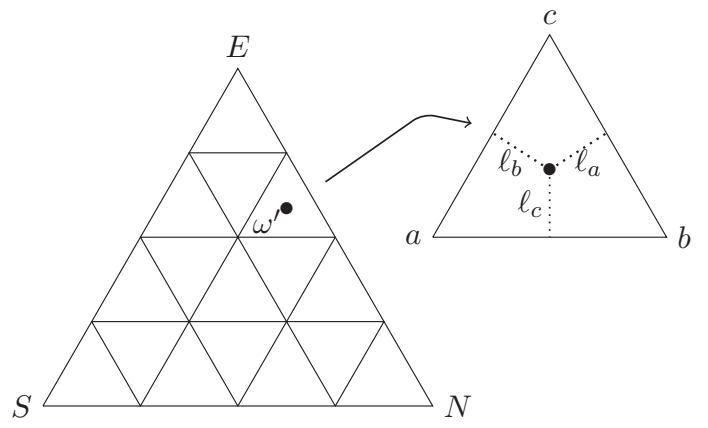

$$
\begin{aligned}
& \omega^{\prime}=\left(s^{\prime}, n^{\prime}, e^{\prime}\right)=\left(\frac{1}{12}, \frac{1}{3}, \frac{7}{12}\right) \\
& a=\left(\left\lceil s^{\prime}\right\rceil,\left\lfloor n^{\prime}\right\rfloor,\left\lfloor e^{\prime}\right\rfloor\right)=\left(\frac{1}{4}, \frac{1}{4}, \frac{1}{2}\right) \\
& b=\left(\left\lfloor s^{\prime}\right\rfloor,\left\lceil n^{\prime}\right\rceil,\left\lfloor e^{\prime}\right\rfloor\right)=\left(0, \frac{1}{2}, \frac{1}{2}\right) \\
& c=\left(\left\lfloor s^{\prime}\right\rfloor,\left\lfloor n^{\prime}\right\rfloor,\left\lceil e^{\prime}\right\rceil\right)=\left(0, \frac{1}{4}, \frac{3}{4}\right) \\
& \ell_{a}=s^{\prime}-\left\lfloor s^{\prime}\right\rfloor=\frac{1}{12} \\
& \ell_{b}=n^{\prime}-\left\lfloor n^{\prime}\right\rfloor=\frac{1}{12} \\
& \ell_{c}=e^{\prime}-\left\lfloor e^{\prime}\right\rfloor=\frac{1}{12}
\end{aligned}
$$

Fig. 1. An illustration of the discretized state space and the discretized transition mapping.

sets:

$$
\begin{aligned}
\Delta\left(\omega^{\prime}\right)= & \operatorname{ch}\left\{\left(\left\lceil s^{\prime}\right\rceil,\left\lfloor n^{\prime}\right\rfloor,\left\lfloor e^{\prime}\right\rfloor\right),\left(\left\lfloor s^{\prime}\right\rfloor,\left\lceil n^{\prime}\right\rceil,\left\lfloor e^{\prime}\right\rfloor\right),\left(\left\lfloor s^{\prime}\right\rfloor,\left\lfloor n^{\prime}\right\rfloor,\left\lceil e^{\prime}\right\rceil\right)\right\} \\
& \cap \Omega
\end{aligned}
$$

and

$$
\begin{aligned}
\nabla\left(\omega^{\prime}\right)= & \operatorname{ch}\left\{\left(\left\lfloor s^{\prime}\right\rfloor,\left\lceil n^{\prime}\right\rceil,\left\lceil e^{\prime}\right\rceil\right),\left(\left\lceil s^{\prime}\right\rceil,\left\lfloor n^{\prime}\right\rfloor,\left\lceil e^{\prime}\right\rceil\right),\left(\left\lceil s^{\prime}\right\rceil,\left\lceil n^{\prime}\right\rceil,\left\lfloor e^{\prime}\right\rfloor\right)\right\} \\
& \cap \Omega,
\end{aligned}
$$

where $\lfloor x\rfloor(\lceil x\rceil)$ refers to the nearest element in $K$ less (larger) than or equal to $x$ and ch denotes the convex hull of a set.

There are three possible cases. Either all of $s^{\prime}, n^{\prime}$, and $e^{\prime}$ are integer multiples of $1 / k$, or exactly one of them is an integer multiple of $1 / k$, or none of them is so. Since $s^{\prime}+n^{\prime}+e^{\prime}=1$, it is not possible that exactly two of them are integer multiples of $1 / k$.

In the first case, it holds that $\omega^{\prime} \in \widehat{\Omega}$, so is a vertex of the triangulated state space, and $\Delta\left(\omega^{\prime}\right)=\nabla\left(\omega^{\prime}\right)=\left\{\omega^{\prime}\right\}$.

In the second case, consider the subcase where $s^{\prime}$ is an integer multiple of $1 / k$, whereas $n^{\prime}$ and $e^{\prime}$ are not. We will restrict attention to this subcase, since the other two subcases are similar. It holds that $s^{\prime}+\left\lfloor n^{\prime}\right\rfloor+\left\lceil e^{\prime}\right\rceil=1$ and that $s^{\prime}+\left\lceil n^{\prime}\right\rceil+\left\lfloor e^{\prime}\right\rfloor=$ 1 , whereas $s^{\prime}+\left\lfloor n^{\prime}\right\rfloor+\left\lfloor e^{\prime}\right\rfloor=1-1 / k$ and $s^{\prime}+\left\lceil n^{\prime}\right\rceil+\left\lceil e^{\prime}\right\rceil=1+1 / k$, so both $\left(s^{\prime},\left\lfloor n^{\prime}\right\rfloor,\left\lfloor e^{\prime}\right\rfloor\right)$ and $\left(s^{\prime},\left\lceil n^{\prime}\right\rceil,\left\lceil e^{\prime}\right\rceil\right)$ do not belong to $\Omega$. Since $\Delta\left(\omega^{\prime}\right)$ and $\nabla\left(\omega^{\prime}\right)$ are subsets of $\Omega$, we have that

$\Delta\left(\omega^{\prime}\right)=\nabla\left(\omega^{\prime}\right)=\operatorname{ch}\left\{\left(s^{\prime},\left\lfloor n^{\prime}\right\rfloor,\left\lceil e^{\prime}\right\rceil\right),\left(s^{\prime},\left\lceil n^{\prime}\right\rceil,\left\lfloor e^{\prime}\right\rfloor\right)\right\}$,

so $\omega^{\prime}$ is on an edge.

In the third case, there are two subcases. It holds that either $\left\lfloor s^{\prime}\right\rfloor+\left\lfloor n^{\prime}\right\rfloor+\left\lfloor e^{\prime}\right\rfloor=1-1 / k$ or $\left\lfloor s^{\prime}\right\rfloor+\left\lfloor n^{\prime}\right\rfloor+\left\lfloor e^{\prime}\right\rfloor=1-2 / k$. In the first subcase, it holds that $\left\lceil s^{\prime}\right\rceil+\left\lfloor n^{\prime}\right\rfloor+\left\lfloor e^{\prime}\right\rfloor=1,\left\lfloor s^{\prime}\right\rfloor+\left\lceil n^{\prime}\right\rceil+$ $\left\lfloor e^{\prime}\right\rfloor=1$, and $\left\lfloor s^{\prime}\right\rfloor+\left\lfloor n^{\prime}\right\rfloor+\left\lceil e^{\prime}\right\rceil=1$, and $\omega^{\prime}$ belongs to $\Delta\left(\omega^{\prime}\right)$. In the second subcase, it holds that $\left\lceil s^{\prime}\right\rceil+\left\lceil n^{\prime}\right\rceil+\left\lfloor e^{\prime}\right\rfloor=1,\left\lceil s^{\prime}\right\rceil+$ $\left\lfloor n^{\prime}\right\rfloor+\left\lceil e^{\prime}\right\rceil=1$, and $\left\lfloor s^{\prime}\right\rfloor+\left\lceil n^{\prime}\right\rceil+\left\lceil e^{\prime}\right\rceil=1$, and $\omega^{\prime}$ belongs to $\nabla\left(\omega^{\prime}\right)$.

Contingent on $\omega^{\prime}$ being in $\Delta\left(\omega^{\prime}\right)$ or $\nabla\left(\omega^{\prime}\right)$, we specify the discretized transition probabilities. If $\omega^{\prime}=Q(\widehat{\omega}, p(\widehat{\omega}))$ is an element of $\Delta\left(\omega^{\prime}\right)$, then the probability $\widehat{Q}\left(\widehat{\omega}^{\prime} \mid \widehat{\omega}, p(\widehat{\omega})\right)$ that state $\widehat{\omega}^{\prime}$ is reached when price $p(\widehat{\omega})$ is chosen at state $\widehat{\omega}$ is given by

$\widehat{Q}\left(\widehat{\omega}^{\prime} \mid \widehat{\omega}, p(\widehat{\omega})\right)= \begin{cases}k \cdot\left(s^{\prime}-\left\lfloor s^{\prime}\right\rfloor\right) & \text { if } \widehat{\omega}^{\prime}=\left(\left\lceil s^{\prime}\right\rceil,\left\lfloor n^{\prime}\right\rfloor,\left\lfloor e^{\prime}\right\rfloor\right) \\ k \cdot\left(n^{\prime}-\left\lfloor n^{\prime}\right\rfloor\right) & \text { if } \widehat{\omega}^{\prime}=\left(\left\lfloor s^{\prime}\right\rfloor,\left\lceil n^{\prime}\right\rceil,\left\lfloor e^{\prime}\right\rfloor\right) \\ k \cdot\left(e^{\prime}-\left\lfloor e^{\prime}\right\rfloor\right) & \text { if } \widehat{\omega}^{\prime}=\left(\left\lfloor s^{\prime}\right\rfloor,\left\lfloor n^{\prime}\right\rfloor,\left\lceil e^{\prime}\right\rceil\right) \\ 0 & \text { otherwise. }\end{cases}$

If $\omega^{\prime}=Q(\widehat{\omega}, p(\widehat{\omega}))$ is an element of $\nabla\left(\omega^{\prime}\right)$, then

$\widehat{Q}\left(\widehat{\omega}^{\prime} \mid \widehat{\omega}, p(\widehat{\omega})\right)= \begin{cases}k \cdot\left(\left\lceil s^{\prime}\right\rceil-s^{\prime}\right) & \text { if } \widehat{\omega}^{\prime}=\left(\left\lfloor s^{\prime}\right\rfloor,\left\lceil n^{\prime}\right\rceil,\left\lceil e^{\prime}\right\rceil\right) \\ k \cdot\left(\left\lceil n^{\prime}\right\rceil-n^{\prime}\right) & \text { if } \widehat{\omega}^{\prime}=\left(\left\lceil s^{\prime}\right\rceil,\left\lfloor n^{\prime}\right\rfloor,\left\lceil e^{\prime}\right\rceil\right) \\ k \cdot\left(\left\lceil e^{\prime}\right\rceil-e^{\prime}\right) & \text { if } \widehat{\omega}^{\prime}=\left(\left\lceil s^{\prime}\right\rceil,\left\lceil n^{\prime}\right\rceil,\left\lfloor e^{\prime}\right\rfloor\right) \\ 0 & \text { otherwise. }\end{cases}$

For the first of the two contingencies, the situation is illustrated graphically in Fig. 1.
We show next that the expected value of the probability distribution on the discretized state space is equal to $\omega^{\prime}$, so

$$
\sum_{\widehat{\omega} \in \widehat{\Omega}} \widehat{Q}\left(\widehat{\omega}^{\prime} \mid \widehat{\omega}, p(\widehat{\omega})\right) \widehat{\omega}^{\prime}=Q(\widehat{\omega}, p(\widehat{\omega}))=\omega^{\prime} .
$$

For $\omega^{\prime} \in \Delta\left(\omega^{\prime}\right)$, it holds that the left-hand size in the above expression is equal to

$$
\begin{aligned}
& k \cdot\left(s^{\prime}-\left\lfloor s^{\prime}\right\rfloor\right) \cdot\left(\begin{array}{l}
\left\lceil s^{\prime}\right\rceil \\
\left\lfloor n^{\prime}\right\rfloor \\
\left\lfloor e^{\prime}\right\rfloor
\end{array}\right)+k \cdot\left(n^{\prime}-\left\lfloor n^{\prime}\right\rfloor\right) \cdot\left(\begin{array}{l}
\left\lfloor s^{\prime}\right\rfloor \\
\left\lceil n^{\prime}\right\rceil \\
\left\lfloor e^{\prime}\right\rfloor
\end{array}\right) \\
& +k \cdot\left(e^{\prime}-\left\lfloor e^{\prime}\right\rfloor\right) \cdot\left(\begin{array}{l}
\left\lfloor s^{\prime}\right\rfloor \\
\left\lfloor n^{\prime}\right\rfloor \\
\left\lceil e^{\prime}\right\rceil
\end{array}\right) \\
& =k \cdot\left(s^{\prime}-\left\lfloor s^{\prime}\right\rfloor\right) \cdot\left(\begin{array}{c}
\left\lfloor s^{\prime}\right\rfloor+\frac{1}{k} \\
\left\lfloor n^{\prime}\right\rfloor \\
\left\lfloor e^{\prime}\right\rfloor
\end{array}\right) \\
& +k \cdot\left(n^{\prime}-\left\lfloor n^{\prime}\right\rfloor\right) \cdot\left(\begin{array}{c}
\left\lfloor s^{\prime}\right\rfloor \\
\left\lfloor n^{\prime}\right\rfloor+\frac{1}{k} \\
\left\lfloor e^{\prime}\right\rfloor
\end{array}\right)+k \cdot\left(e^{\prime}-\left\lfloor e^{\prime}\right\rfloor\right) \cdot\left(\begin{array}{c}
\left\lfloor s^{\prime}\right\rfloor \\
\left\lfloor n^{\prime}\right\rfloor \\
\left\lfloor e^{\prime}\right\rfloor+\frac{1}{k}
\end{array}\right) \\
& =\left(\begin{array}{l}
\left\lfloor s^{\prime}\right\rfloor \\
\left\lfloor n^{\prime}\right\rfloor \\
\left\lfloor e^{\prime}\right\rfloor
\end{array}\right)+\left(\begin{array}{l}
s^{\prime}-\left\lfloor s^{\prime}\right\rfloor \\
n^{\prime}-\left\lfloor n^{\prime}\right\rfloor \\
e^{\prime}-\left\lfloor e^{\prime}\right\rfloor
\end{array}\right)=\left(\begin{array}{l}
s^{\prime} \\
n^{\prime} \\
e^{\prime}
\end{array}\right),
\end{aligned}
$$

where the second equality makes use of the fact that $\left(s^{\prime}-\left\lfloor s^{\prime}\right\rfloor\right)+$ $\left(n^{\prime}-\left\lfloor n^{\prime}\right\rfloor\right)+\left(e^{\prime}-\left\lfloor e^{\prime}\right\rfloor\right)=1 / k$. The derivation for $\omega^{\prime} \in \nabla\left(\omega^{\prime}\right)$ is analogous.

\subsection{Existence}

The next question is whether an optimal pricing policy exists for the Markov decision problem with state space $\widehat{\Omega}$, action set $\mathbb{R}_{+}$ in each state, and transitions as determined by $\widehat{Q}$. Unfortunately, the unboundedness of the action set means that standard existence results like for instance Theorem 6.2.10 in Puterman (1994) cannot be applied. Nevertheless, existence of an optimal pricing policy can be established by the following argument.

For every state $\widehat{\omega}$, consider first the highest price $\bar{p}(\widehat{\omega})$ that would maximize the firm's instantaneous profits. The continuity of the instantaneous profits in $p(\widehat{\omega})$, the fact that instantaneous profits are strictly positive for every $p(\widehat{\omega})>\mu$, and, since $\lambda>0$, the convergence of instantaneous profits to zero if $p(\widehat{\omega}) \rightarrow \infty$, guarantees that such a price exists. We show that $\bar{p}(\widehat{\omega})$ is an upper bound for the price set by the optimal pricing policy in state $\widehat{\omega}$. 
We call the real-valued vector $v$ with components indexed by $\widehat{\omega} \in \widehat{\Omega}$ monotonic if for every $\widehat{\omega}_{1}=\left(s_{1}, n_{1}, e_{1}\right)$ and $\widehat{\omega}_{2}=\left(s_{2}, n_{2}, e_{2}\right)$ such that $s_{1} \leq s_{2}, n_{1} \geq n_{2}$, and $e_{1} \geq e_{2}$ it holds that $v_{\widehat{\omega}_{1}} \leq v_{\widehat{\omega}_{2}}$. The set of all monotonic vectors $v$ is denoted by $M$. Monotonic $v$ 's arise naturally in our model, since states with higher market shares for the firm, a smaller P2P network, and a smaller unserved market, are more attractive for the firm.

We argue next that for every $\widehat{\omega} \in \widehat{\Omega}$, for every monotonic $v$,

$\max _{p(\widehat{\omega}) \in \mathbb{R}_{+}} \pi(\widehat{\omega}, p(\widehat{\omega}))+\delta \sum_{\widehat{\omega}^{\prime} \in \widehat{\Omega}} \widehat{Q}\left(\widehat{\omega}^{\prime} \mid \widehat{\omega}, p(\widehat{\omega})\right) v_{\widehat{\omega}^{\prime}}$

exists. Our functional forms are such that a higher price leads to higher transition probabilities to states with lower values of $s$ and higher values of $n$ and $e$. Monotonicity of $v$ then implies that $p(\widehat{\omega})$ leads to a lower value of the expression in (1) than $\bar{p}(\widehat{\omega})$ if $p(\widehat{\omega})>\bar{p}(\widehat{\omega})$. The continuity of the expression in $(1)$ in $p(\widehat{\omega})$ and the compactness of $[0, \bar{p}(\widehat{\omega})]$ implies that the maximum exists. We denote the maximum by $L_{\widehat{\omega}}(v)$ and the vector of maxima across states in $\widehat{\Omega}$ by $L(v)$.

Consider some $v \in M$, two states $\widehat{\omega}_{1}=\left(s_{1}, n_{1}, e_{1}\right)$ and $\widehat{\omega}_{2}=$ $\left(s_{2}, n_{2}, e_{2}\right)$ such that $s_{1} \leq s_{2}, \quad n_{1} \geq n_{2}$, and $e_{1} \geq e_{2}$, and let $p^{*}\left(\widehat{\omega}_{1}\right)$ be a price that maximizes the expression in (1). Since $\pi\left(\widehat{\omega}_{2}, p^{*}\left(\widehat{\omega}_{1}\right)\right) \geq \pi\left(\widehat{\omega}_{1}, p^{*}\left(\widehat{\omega}_{1}\right)\right)$ and the transitions from $\widehat{\omega}_{2}$ induced by $p^{*}\left(\widehat{\omega}_{1}\right)$ are to states with higher values of $s$ and lower values of $n$ and $e$ than the transitions from $\widehat{\omega}_{1}$ induced by $p^{*}\left(\widehat{\omega}_{1}\right)$, monotonicity of $v$ implies that

$$
\begin{aligned}
& \pi\left(\widehat{\omega}_{2}, p^{*}\left(\widehat{\omega}_{1}\right)\right)+\delta \sum_{\widehat{\omega} \in \widehat{\Omega}} Q\left(\widehat{\omega} \mid \widehat{\omega}_{2}, p^{*}\left(\widehat{\omega}_{1}\right)\right) v_{\widehat{\omega}} \geq \pi\left(\widehat{\omega}_{1}, p^{*}\left(\widehat{\omega}_{1}\right)\right) \\
& +\delta \sum_{\widehat{\omega} \in \widehat{\Omega}} Q\left(\widehat{\omega} \mid \widehat{\omega}_{1}, p^{*}\left(\widehat{\omega}_{1}\right)\right) v_{\widehat{\omega}}=L_{\widehat{\omega}_{1}}(v),
\end{aligned}
$$

and therefore that $L_{\widehat{\omega}_{2}}(v) \geq L_{\widehat{\omega}_{1}}(v)$. The function $L$ therefore maps $M$ into $M$.

It follows from standard arguments in the literature on Markov decision processes, see Theorem 6.2.3 in Puterman (1994), that $L$ is a contraction mapping, so has a unique fixed point, and that a fixed point of $L$ corresponds to an optimal pricing policy, see Theorem 6.2.3 in Puterman (1994). We have therefore shown the existence of an optimal pricing policy. It also holds that randomized or non-stationary policies do not lead to higher values of the objective function than the optimal deterministic stationary policy, see Theorem 5.5.3b and Proposition 6.2.1 in Puterman (1994).

\subsection{Policy iteration algorithm}

We present an algorithm to approximate the optimal pricing policy for the discretized state space.

\section{Policy iteration algorithm}

initialize Choose stopping criterion $\xi>0$ and an arbitrary starting policy $p_{0}: \widehat{\Omega} \rightarrow \mathbb{R}_{+}$.

Set $i=1$.

loop

1. Compute the present value of $p_{i-1}$ for each possible starting state in $\widehat{\Omega}$.

That is, solve the system of linear equations

$V\left(\widehat{\omega}, p_{i-1}\right)=\pi\left(\widehat{\omega}, p_{i-1}(\widehat{\omega})\right)+\delta \cdot \sum_{\widehat{\omega}^{\prime} \in \widehat{\Omega}} \widehat{Q}\left(\widehat{\omega}^{\prime} \mid \widehat{\omega}, p_{i-1}(\widehat{\omega})\right) \cdot V\left(\widehat{\omega}^{\prime}, p_{i-1}\right)$.

2. Improve the policy for each state in $\widehat{\Omega}$.

That is, solve for each state $\widehat{\omega}$ the problem

$p_{i}(\widehat{\omega}):=\operatorname{argmax}_{z} \pi(\widehat{\omega}, z)+\delta \cdot \sum_{\widehat{\omega}^{\prime} \in \hat{\Omega}} \widehat{Q}\left(\widehat{\omega}^{\prime} \mid \widehat{\omega}, z\right) \cdot V\left(\widehat{\omega}^{\prime}, p_{i-1}\right)$.

3. Terminate loop if the improvement is negligible:

if $\left\|p_{i}-p_{i-1}\right\|_{\infty}<\xi$ :

then Terminate loop and return $p_{i}$ as the optimal pricing policy.

else Increase $i$ with one and resume at step 1 .

In step 2 of the loop, given a certain policy, the optimal oneshot deviation with respect to this policy is determined for each possible state. The stationary pricing policy that is composed from the state prices that induce optimal one-shot improvements guarantees at least the same present value for each possible starting state and, hence, is a better pricing policy relative to the previous one. This is based on two arguments. First, a one-shot improvement in a state leads to a stationary improvement whenever this state occurs. Second, any improvement implemented in one state implies a weak improvement in all other states. From the one-deviation principle it follows that once no (non-negligible) improvement can be found, an (almost) optimal pricing policy is reached. To sum up, any iteration throughout the running of the policy iteration algorithm guarantees an improvement and, once the algorithm terminates, it returns a (nearly) optimal pricing policy.

The loop terminates when the change in the pricing policy $\left\|p_{i}-p_{i-1}\right\|_{\infty}$ is less than or equal to the stopping criterion $\xi$, where by definition of the infinity norm $\left\|p_{i}-p_{i-1}\right\|_{\infty}=$ $\max _{\widehat{\omega} \in \widehat{\Omega}}\left|p_{i}(\widehat{\omega})-p_{i-1}(\widehat{\omega})\right|$. That is, the loop terminates when there is no state for which the price has changed by more than $\xi$ during the respective iteration. A smaller value for $\xi$ leads the algorithm to terminate with a better approximation of the optimal pricing policy.

In our numerical derivations, we used a bracketing algorithm to numerically solve the maximization problems in step 2 at every iteration. ${ }^{4}$ The procedure underlying this algorithm is analogous to the bisection algorithm for root-solving. Whereas the bisection algorithm starts with two initial points with unequal sign, the bracketing algorithm starts with three initial points (say, $x_{1}, y_{1}$, and $z_{1}$ with $x_{1}<y_{1}<z_{1}$ ) with the property that the function value is highest at the middle point $y_{1}$. Next, at every iteration, the midpoint of the largest of the two intervals that are determined by the three points (i.e., $\left[x_{1}, y_{1}\right]$ and $\left.\left[y_{1}, z_{1}\right]\right)$ is taken. If the function value at the midpoint $m$ is less than the function value at the middle point $y_{1}$, then the larger interval is bisected (i.e., $\left(x_{2}, y_{2}, z_{2}\right):=\left(m, y_{1}\right.$, $\left.z_{1}\right)$ or $\left(x_{2}, y_{2}, z_{2}\right):=\left(x_{1}, y_{1}, m\right)$ depending on whether the first or the second interval is the largest). Otherwise, the smaller interval is dropped (i.e., $\left(x_{2}, y_{2}, z_{2}\right):=\left(x_{1}, m, y_{1}\right)$ or $\left(x_{2}, y_{2}, z_{2}\right):=\left(y_{1}, m\right.$, $z_{1}$ ) depending on whether the first or the second interval is the largest). This procedure is iterated until the search area has shrunk to a size less than a predefined tolerance level.

One challenge towards implementing the bracketing algorithm is to find three starting points $x_{1}, y_{1}$, and $z_{1}$ with the property that function value is highest at $y_{1}$. We take $x_{1}$ equal to 0 . For $z_{1}$ we take any price sufficiently high such that the corresponding function value is less than the function value at $z_{1} / 2$. Such a price is guaranteed to exist. We need to determine a middle point $y_{1}$ such that the function value at $y_{1}$ exceeds the function value at $x_{1}$ and $z_{1}$. The function value at a price equal to $\left(x_{1}+z_{1}\right) / 2=z_{1} / 2$ is above the function value at $z_{1}$ by our choice of $z_{1}$. If the function value at $z_{1} / 2$ is above the function value at $x_{1}=0$, then we take $y_{1}$ equal to $z_{1} / 2$. Otherwise, the function value at $x_{1}=0$ is above the function value at $z_{1}$ and we consider a price equal to $z_{1} / 4$. If the function value at $z_{1} / 4$ is above the function value at $x_{1}=0$, then we take $y_{1}$ equal to $z_{1} / 4$. Otherwise, we consider a price equal to $z_{1} / 8$. We continue in this fashion and will either end up at some iteration $j$ such that $y_{1}=z_{1} / 2^{j}$ or $z_{1} / 2^{j}<\xi$. In the first case, a triple with the desired properties is found and the bracketing algorithm is started; in the second case, a price of zero is optimal in the given state at the given iteration.

\section{Model calibration and benchmark outcomes}

In order for the model to generate meaningful real-life insights, we calibrate the parameters to be consistent with real-life data. The model contains two types of parameters. The first type are those whose values are directly retrievable from consumer surveys

\footnotetext{
4 See Judd (1998, p. 94)
} 
Table 1

\begin{tabular}{llllllllll} 
Legal sales. & \multicolumn{1}{l}{ (1999 } & 2000 & 2001 & 2002 & 2003 & 2004 & 2005 & 2006 & 2007 \\
\hline Physical CDs (million \$) & 12816.3 & 13214.5 & 12909.4 & 12044.1 & 11232.9 & 11446.5 & 10520.2 & 9372.6 & 7452.3 \\
Digital singles (million \$) & 0.0 & 0.0 & 0.0 & 0.0 & 0.0 & 138.0 & 363.3 & 580.6 & 801.6 \\
Digital albums (million \$) & 0.0 & 0.0 & 0.0 & 0.0 & 0.0 & 45.5 & 135.7 & 275.9 & 424.9 \\
Total legal sales (million \$) & 12816.3 & 13214.5 & 12909.4 & 12044.1 & 11232.9 & 11630.0 & 11019.2 & 10229.1 & 8678.8 \\
Number physical CDs (million) & 938.9 & 942.5 & 881.9 & 803.3 & 746.0 & 767.0 & 705.4 & 619.7 & 511.1 \\
Number total legal sales (million) & 938.9 & 942.5 & 881.9 & 803.3 & 746.0 & 779.3 & 738.9 & 676.3 & 595.2 \\
\hline
\end{tabular}

and financial statements. The second type are not directly retrievable and are calibrated in order for the model outcomes to fit reallife data on market outcomes. We adopt two benchmark scenarios: the situation before P2P was made available to the public and the situation when legal digital sales started to soar. More precisely, we take the years 1999 and 2007 for calibration. This allows us to analyze the order of magnitude of the societal impacts of the P2P networks on firms' profits and consumers' welfare in that period. Thus, in this model, we speak of numbers in dollar terms.

\subsection{Data and evidence}

First of all, we start with the $C D$ prices over the years. According to the aggregate data from RIAA (2007), the average price of a $\mathrm{CD}$ in the U.S. has been kept at around $\$ 14$ over the years. However, the real prices, if one takes inflation into account, have shown minor fluctuations with a mildly decreasing trend. In our model, therefore, we should find CD prices at a level around \$13.

Next we turn to $C D$ sales. Table 1 presents some key figures coming from the year-end report from RIAA (2009). According to these numbers, the record companies shipped about 938.9 million copies of CDs to the consumers in the year 1999. Up to 2007, legal digital sales were still not very significant. For instance, RIAA (2009) reports that the market value of digitally downloaded singles in 2007 was equal to $\$ 801.6$ million, digitally downloaded albums $\$ 424.9$ million, whereas the market value of physical CDs was equal to $\$ 7452.3$ million. Digital sales soared by $30 \%$ in 2008 , while physical sales plummeted by $27 \%$ in that year. Since the market structure has changed so significantly in 2008 , we limit our calculations to the period starting in 1999 and ending in 2007. The RIAA (2009) report reveals that in 2007 the equivalent of 595.2 million CDs were sold legally. This suggests that the $\mathrm{CD}$ sales have decreased by about $32 \%$ in 8 years. This implies that in our model, the sales in the store in the last period should be about $68 \%$ of those in the first period.

Finally, the P2P network size. Napster was introduced to the general public in the year 1999. We therefore take the network size in the year 1999 to be 0 . Now the question is: how many albums are being downloaded via P2P networks in 2007? Siwek (2007), based on a report by the IFPI, makes an estimate of 20 billion illegal downloads worldwide for 2006 versus 2.3 billion legally sold physical, implying that $n / s$ is around 9 in 2006. IFPI (2008) reports that in 2007 "Tens of billions of illegal music files are traded annually worldwide at an estimated ratio of 20 illegal downloads for every track sold," yielding an estimate for $n / s$ equal to 20 in 2007. In the calculations resulting from the calibrated model, we will aim at a value of $n / s$ of 16 for 2007, which is in between the two reported values and a bit closer to that reported for 2007 .

\subsection{Parameter calibration}

The survey reported in Rob and Waldfogel (2006) indicates that in the period December 2003 and February 2004 the average willingness to pay of purchased CDs was around \$15.91. This means that the parameter $\beta$ should be set such that the gross valuation of CDs purchased in 2003, that includes the random term $\left(\varepsilon_{S}\right)$ and eventual switching costs, is close to this number. We find that for $\beta=11$, we obtain a gross valuation of purchased CDs equal to $\$ 15.75$ at the state and price in 2003 (as presented in Table 3), which is very close to the number reported in the survey. Since we have no reason to believe that the consumption value of illegally downloaded music is very different from the consumption value of a legally acquired $\mathrm{CD}$, we set $\gamma$ equal to $\beta$ for the situation with P2P. Indeed, there exist consumers that regard a legal product more valuable than an illegal one, because of ensured quality, the possibility of loss of private information and being infected by viruses when dealing with P2P sites, etc. However, there also exist many consumers that prefer illegal digital versions to legal physical ones for various reasons, including portability, ease in exchange, ability to play on multiple devices, and no need to acquire (multiple) peripheral hardware. Via the error terms in our logistic choice framework, our model allows for both types of consumers. To obtain the starting scenario of the year 1999, we take $\gamma=-1000$, implying that the probability of a consumer choosing the P2P network is approximately equal to zero. This is simply a modeling trick to obtain the situation without a P2P network as a special case of our model.

In a study done by Peitz and Waelbroeck (2005), the authors show a report from IFPI that explains the break-down of the average cost of a CD. This can be estimated to be about $€ 13$ including taxes. However, since in our model we look at all figures in dollar terms, it follows that the per unit cost $\mu$ in our model should be around $\$ 10$. The discount factor $\delta$ can be taken safely as 0.95 according to the convention of an interest rate equal to approximately $5 \%$.

The generic cost factor of downloading $\sigma$ and the parameter that captures the curvature of the downloading cost function $\rho$ are model specific and we choose $\rho=0.025$ and $\sigma=0.5$ to get a realistic specification of downloading costs. Since the cost function is $c(n)=\sigma /(n+\rho)$, this implies that when no one is using the network, it costs $\$ 20$ to download an album, which is more expensive than buying it in the store. However, when $7.5 \%$ of the total market downloads an album, the downloading cost drops significantly to $\$ 5$, which might be tempting for many consumers, though not all. As around half of the market downloads, the cost drops further towards $\$ 1$, which makes it seriously attractive for everyone. Finally, when the whole population downloads, the cost drops to the minimum of about $\$ 0.5$.

The consumer heterogeneity parameter $\lambda$ and the switching cost $\tau$ are determined by calibration and are chosen such that both the store and the network achieve realistic quantities in both benchmark scenarios. The quantities we want to match are the realized sales ratio $s_{2007} / s_{1999}=595.2 / 938.9=0.63$ and the network to sales ratio in $2007, n_{2007} / s_{2007}=16$. We choose a grid of potential values for $\lambda$ and $\tau$. For each $(\lambda, \tau)$ pair we compute the optimal pricing policy in the absence of the P2P network and determine the steady state of 1999 in the absence of the P2P network by iterating the resulting matrix of transition probabilities. Next we compute the optimal pricing policy in the presence of the P2P network and use that policy and the steady state of 1999 to compute 
Table 2

Parameter description and values before and after P2P.

\begin{tabular}{llll}
\hline Parameter & Description & Before P2P & After P2P \\
\hline$\beta$ & Utility legal product & 11 & 11 \\
$\gamma$ & Utility illegal download & -1000 & 11 \\
$\sigma$ & Generic cost factor of downloading & 0.5 & 0.5 \\
$\rho$ & Cost function parameter & 0.025 & 0.025 \\
$\tau$ & Switching costs & 12 & 12 \\
$\lambda$ & Homogeneity of consumers' preferences & 0.28 & 0.28 \\
$\delta$ & Discount factor & 0.95 & 0.95 \\
$\mu$ & Per unit production costs & 10 & 10 \\
\hline
\end{tabular}

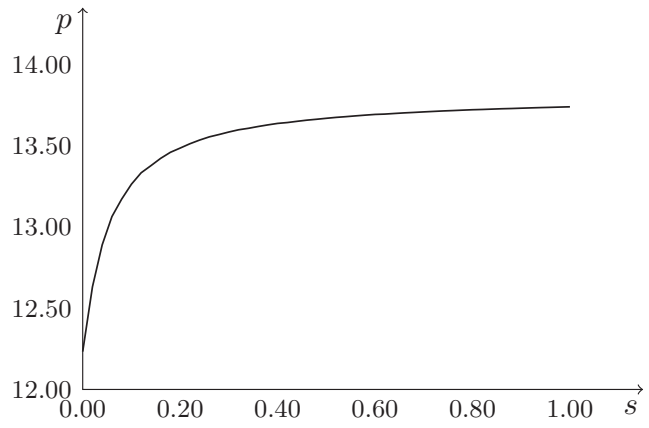

Fig. 2. Pricing policy without P2P.

the resulting $n_{2007} / s_{2007}$. This leads to values for $\lambda$ of 0.28 and $\tau$ of 12 .

Table 2 summarizes the chosen parameter values with all prices being in dollar terms.

\section{Model outcomes and analysis}

The numerical method presented in Section 3 is programmed into a series of Matlab routines. ${ }^{5}$ We ran the resulting program using the parameter values of Table 2 . For the discretization, we opt for a grid size of $1 / 50$, i.e. $k=50$; the tolerance level for the pricing policy to convergence is set to 4 digits after the decimal for the maximum state-wise difference between consecutive iterations. ${ }^{6}$ We obtain outcomes such as pricing policy, profits, state dynamics, probability distribution over states, and welfare.

We start by computing the optimal pricing policy in 1999; that is, before the introduction of P2P. Fig. 2 indicates the prices charged by the firm in the different states in the year 1999 before P2P was available. Since this case corresponds to $\gamma=-1000$, the value of $s$ is a sufficient state variable for the firm. The firm charges higher prices in the states where it has higher market shares in a monotonic fashion. This seems natural given the presence of the switching cost.

Regardless of which distribution of states we start the Markov process from, given the optimal pricing policy and the induced process of state-transitions, we always end up in a unique steady state distribution. In this steady state, it holds that $s=0.032$, the network size is $n=0$ by construction, and $e=0.968$. The low value of $s$ reflects that without the P2P network much less music is acquired by the consumers. The expected steady-state price charged by the firm is $\$ 12.79$.

Fig. 3 illustrates the firm's optimal pricing policy after the introduction of P2P, by plotting the firm's price choices as a function of its market share for five different values of the network

\footnotetext{
5 The Matlab routines are available upon request.

6 The tolerance level of the bracketing algorithm for policy improvement is set to 6 digits after the decimal.
}

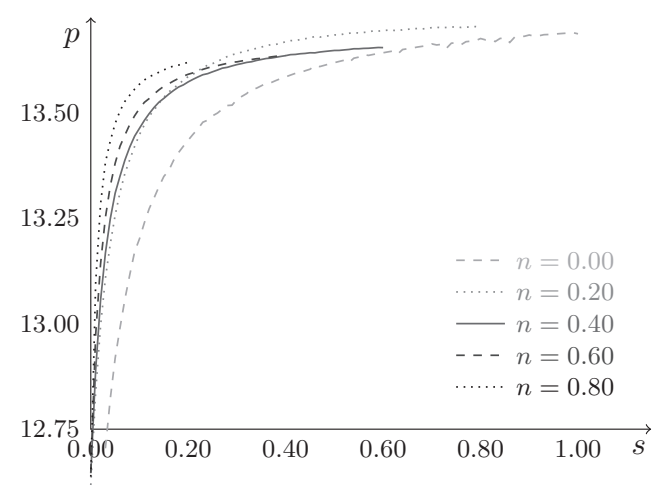

Fig. 3. Price policy with P2P. Prices are plotted as a function of the firm's market share for different values of network size.

size $(n \in\{0.00,0.20,0.40,0.60,0.80\})$. Generally the firm's price is, for given network size, increasing in its market share. It follows from the figure that for a given market share of the firm, the firm's pricing is typically non-monotonic in the size of the network. As an example, for $s=0.30$, it holds that the price is highest when $n=0.20$, followed by $n=0.60, n=0.40$, and $n=0.00$.

The two main forces at work are the following. Setting a low price leads to low instantaneous profits, but by attracting customers away from the P2P network, to higher future market shares and thereby higher future profits. Setting a high price leads to high instantaneous profits by exploiting the installed customer base, but at the same time accommodates the network, leading to lower future market shares and thereby lower future profits. Since, given the size of the P2P network, all the curves are increasing, the larger the market share of the firm, the higher it sets its price, so the exploitation of the installed customer base dominates. Since, given the market share of the firm, a larger P2P network is more attractive because of the lower downloading cost, dynamic considerations to fight the network in order to gain market share tend to become less and less important when the network grows.

At a state with $n=0$, the prices charged in the presence of P2P are lower than before P2P was introduced, in line with standard predictions if a competitor with a close substitute enters the market.

Table 3 shows the evolution of the model's endogenous variables resulting from the introduction of P2P. The columns are arranged in years and the rows show the model outcomes, where $p$, $\pi, c s$, and $w$ stand for price, profit, consumer surplus, and welfare, respectively. The dynamics are obtained from following the Markov process induced by the optimal pricing policy $p^{*}$ of the situation after the introduction of P2P, while starting from the steady state distribution of the situation before the introduction of P2P. Notice that the numbers refer to weighted averages of the state outcomes, where the weight on a particular state is the probability that this state is visited in the respective year. All numbers, except for the prices, are obtained by multiplying the values of the model out- 
Table 3

Evolution of market outcomes over years. All quantities, except prices, are scaled to market values, as described in the main text.

\begin{tabular}{llllllllll}
\hline & 1999 & 2000 & 2001 & 2002 & 2003 & 2004 & 2005 & 2006 & 2007 \\
\hline$p(\$)$ & 12.79 & 12.75 & 12.78 & 12.82 & 12.84 & 12.87 & 12.87 & 12.87 & 12.87 \\
$s$ (billions) & 0.94 & 0.95 & 0.94 & 0.93 & 0.89 & 0.83 & 0.76 & 0.69 & 0.62 \\
$n$ (billions) & 0.00 & 0.08 & 0.23 & 0.62 & 1.61 & 3.29 & 5.37 & 7.56 & 9.69 \\
$\pi$ (\$ billions) & 2.62 & 2.60 & 2.58 & 2.50 & 2.35 & 2.17 & 1.97 & 1.77 & 1.59 \\
$c s$ (\$ billions) & 64.21 & 64.79 & 65.50 & 69.25 & 84.77 & 111.11 & 138.36 & 163.53 & 186.21 \\
$w$ (\$ billions) & 66.83 & 67.39 & 68.08 & 71.85 & 87.12 & 113.28 & 140.33 & 165.30 & 187.80 \\
\hline
\end{tabular}

comes with a factor of 29.3 billion. This scaler is estimated by taking the ratio between the total CD sales of 938.9 million according to the RIAA's year end report, and the CD sales quantity $s$ of 0.032 in our model in 1999.?

The computation of profits $\pi$, consumer surplus $c s$, and total welfare $w$ is as follows. Let $\mathbb{P}$ be the probability distribution on states in $\widehat{\Omega}$ in a particular year. Then we have

$\pi=\sum_{\widehat{\omega} \in \widehat{\Omega}} \mathbb{P}(\widehat{\omega}) \cdot\left(p^{*}(\widehat{\omega})-\mu\right) \cdot d\left(\widehat{\omega}, p^{*}(\widehat{\omega})\right)$.

The consumer surplus is computed at the expected state $\widetilde{\omega}$ and the expected price $\widetilde{p}:^{8}$

$\widetilde{\omega}=\sum_{\widehat{\omega} \in \widehat{\Omega}} \mathbb{P}(\widehat{\omega}) \cdot \widehat{\omega}$,

$\tilde{p}=\sum_{\widehat{\omega} \in \widehat{\Omega}} \mathbb{P}(\widehat{\omega}) \cdot p^{*}(\widehat{\omega})$.

We first determine the conditional consumer surplus at his expected state $\widetilde{\omega}=(\widetilde{s}, \widetilde{n}, \widetilde{e})$ and price $\widetilde{p}$ on being of type $\theta_{S}, \theta_{N}$, and $\theta_{E}$, denoted respectively by $\operatorname{cs}_{S}(\widetilde{\omega}, \widetilde{p}), c s_{N}(\widetilde{\omega}, \widetilde{p})$, and $c s_{E}(\widetilde{\omega}, \widetilde{p})$ :

$$
\begin{aligned}
& \operatorname{cs}_{S}(\widetilde{\omega}, \tilde{p})=\int_{\left(\varepsilon_{S}, \varepsilon_{N}, \varepsilon_{E}\right)} \max \left\{\beta-\tilde{p}+\varepsilon_{S}, \gamma-c(\tilde{n})\right. \\
& \left.-\tau+\varepsilon_{N}, \varepsilon_{E}\right\} \mathrm{d} F\left(\varepsilon_{S}, \varepsilon_{N}, \varepsilon_{E}\right), \\
& \operatorname{cs}_{N}(\tilde{\omega}, \tilde{p})=\int_{\left(\varepsilon_{S}, \varepsilon_{N}, \varepsilon_{E}\right)} \max \left\{\beta-\tilde{p}-\tau+\varepsilon_{S}, \gamma\right. \\
& \left.-c(\tilde{n})+\varepsilon_{N}, \varepsilon_{E}\right\} \mathrm{d} F\left(\varepsilon_{S}, \varepsilon_{N}, \varepsilon_{E}\right), \\
& c S_{E}(\tilde{\omega}, \tilde{p})=\int_{\left(\varepsilon_{S}, \varepsilon_{N}, \varepsilon_{E}\right)} \max \left\{\beta-\tilde{p}-\tau+\varepsilon_{S}, \gamma-c(\tilde{n})\right. \\
& \left.-\tau+\varepsilon_{N}, \varepsilon_{E}\right\} \mathrm{d} F\left(\varepsilon_{S}, \varepsilon_{N}, \varepsilon_{E}\right),
\end{aligned}
$$

where $F$ is the joint distribution where the three error-terms are identically and independently distributed according to a Gumbel extreme value distribution with location parameter 0 and scale parameter $\lambda$. We compute the integrals by means of simulations involving 9 million random draws. Consumer surplus is now equal to

$\left.c S=\widetilde{s} \cdot c s_{S}(\widetilde{\omega}, \tilde{p})+\tilde{n} \cdot c s_{N}(\widetilde{\omega}, \tilde{p})+\widetilde{e} \cdot c s_{E}(\widetilde{\omega}, \widetilde{p})\right)$.

Total welfare follows from the addition of consumer surplus to profits,

$w=\pi+c S$.

The years 1999 and 2007 were used to calibrate some of the model's parameters; so the match with real-life figures in these

\footnotetext{
7 Estimations of the total market size in a similar manner for the period 2000 2007 yield the values 29.1, 27.1, 24.9, 23.8, 26.2, 27.5, 28.7 and 29.6 billion, respectively. We believe the changes in estimated total market sizes are within a bandwidth that we feel comfortable using the fixed figure of 29.3 billion.

${ }^{8}$ An alternative way of deriving the consumer surplus is to first compute the consumer surplus in each discrete state, and next take the weighted average of the resulting consumer surpluses using the probability distribution on states as the weights. We opted for the computationally least expensive method in which integrals over random shocks need to be evaluated in one state only.
}

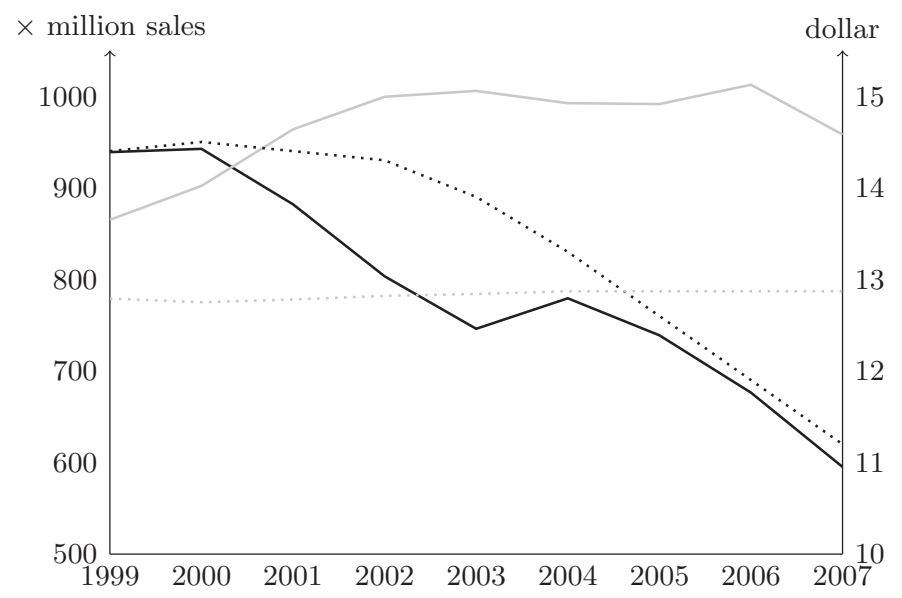

Fig. 4. Annual total legal sales (black; left $y$-axis) and average prices (gray; right $y$-axis) during 1999-2007 on the basis of actual numbers (solid) and the model predictions (dotted).

two periods is quite accurate. The remaining numbers in the table are outcomes of the model, but nevertheless provide quite a good fit to the real-life figures as far as they are available. To visualize some similarities, Fig. 4 presents the annual total legal sales and average prices during 1999-2007 on the basis of actual numbers (taken from Table 1) and the model predictions (taken from Table 3). Surprisingly, the model's outcomes capture the anomaly of the CD sales increase in 2000 , before sales start to drop. The price chosen by the firm in 2000 is somewhat below the one of 1999, which causes sales to increase. In these years, the size of the P2P network is still so small that the firm benefits from setting low prices, thereby delaying the development of the network, and increasing the future profits of the firm.

Now, let us scrutinize some of the key numbers across the years. The firm's profit decreases steadily over the years. By the year 2007, this decrease had led to a huge loss of $\$ 1.0$ billion in annual profits, according to the model's estimation. Consumer surplus, however, increases in the same period by some $\$ 122.0$ billion per annum. As a result of that, total welfare benefits by around $\$ 121.0$ billion per annum.

So far we have assumed the P2P network to cause positive network externalities. As an exercise, we could consider the model for the case where downloading costs are equal to a constant $c$, so independent of the size of the P2P network. Notice that this case is equivalent to simply decreasing $\gamma$ by the amount $c$ and having zero downloading costs. We take $c$ equal to 0.5519 , the steady state value of per capita downloading costs, and present the resulting evolution of market outcomes in Table 4.

Without positive network externalities, the ratio of $n$ to $s$ is 20 in 2000, so higher than our estimated 2007 size of 16 , only one year after the introduction of P2P. Already in 2001, the P2P network would have surpassed the estimated real size of the network in 2007. Very similar effects occur for the sales at the store. With 
Table 4

Evolution of market outcomes over years in the absence of positive network externalities.

\begin{tabular}{llllllllll}
\hline & 1999 & 2000 & 2001 & 2002 & 2003 & 2004 & 2005 & 2006 & 2007 \\
\hline$p(\$)$ & 12.79 & 13.04 & 12.96 & 12.88 & 12.83 & 12.79 & 12.77 & 12.76 & 12.75 \\
$s$ (billions) & 0.94 & 0.57 & 0.36 & 0.24 & 0.18 & 0.14 & 0.12 & 0.11 & 0.10 \\
$n$ (billions) & 0.00 & 11.29 & 17.65 & 21.22 & 23.23 & 24.37 & 25.00 & 25.36 & 25.56 \\
$\pi$ (\$ billions) & 2.62 & 1.10 & 0.74 & 0.53 & 0.42 & 0.35 & 0.32 & 0.30 & 0.28 \\
$c s$ (\$ billions) & 64.21 & 213.99 & 269.78 & 301.17 & 318.82 & 328.75 & 334.33 & 337.48 & 339.25 \\
$w$ (\$ billions) & 66.83 & 215.09 & 270.52 & 301.70 & 319.24 & 329.11 & 334.66 & 337.78 & 339.53 \\
\hline
\end{tabular}

Table 5

Elasticities of steady state outcomes for variables in the rows with respect to the parameters in the columns; without P2P.

\begin{tabular}{lllll}
\hline & $\beta$ & $\tau$ & $\lambda$ & $\mu$ \\
\hline$p$ & -0.0391 & -0.0511 & -0.2706 & 0.8248 \\
$s$ & 4.3531 & -2.9281 & -2.5469 & -3.8094 \\
$\pi$ & 4.1387 & -3.1286 & -3.7327 & -3.6096 \\
$c s$ & 0.2756 & -0.1671 & -1.1318 & -0.2398 \\
$w$ & 0.4277 & -0.2839 & -1.2345 & -0.3719 \\
\hline
\end{tabular}

constant downloading costs, the firm's sales would already have plummeted to a level of 568.4 million in the year 2000, already way below actual sales of 595.2 million in 2007. With constant downloading costs, the model predicts only 102.6 million sales for 2007. The results coming out of the model for 2007 could be improved by significantly increasing the value of switching costs $\tau$ above $\$ 11$ or downloading costs $c$ above 0.5519. Apart from not being realistic, such a change would not capture the dynamics of the network and the firm's market share in any accurate way.

\section{Comparative statics}

The previous section focused on the market outcomes across the years 1999-2007. This section analyzes the effects of small changes in the parameters on the steady state market outcomes.

As a reference point, the comparative statics of the benchmark's starting state in 1999 without P2P are presented in Table 5. The numbers in the cells refer to the elasticities of market outcomes (in rows) with respect to the model's parameters (in columns). Table 6 presents the comparative statics at the steady state resulting from the firm's optimal pricing policy after the appearance of P2P. The steady state in the presence of P2P is computed by starting from the steady state without P2P in 1999 and iterating the matrix of transition probabilities corresponding to the optimal pricing policy in the presence of $\mathrm{P} 2 \mathrm{P}$. The elasticities are computed numerically, i.e. by changing the parameter concerned by a small amount, computing the new optimal pricing policy and the resulting new steady state, and using these values to derive the elasticities of interest.

The intuition behind the numbers in Table 5 compares well to standard intuitions of a monopoly analysis. Meanwhile, according to Table 6 , the model outcomes are generally most sensitive towards changes in the parameters $\beta, \gamma, \lambda$, and $\mu$. In particular, sales quantity and the firm's profit show a substantial increase in $\beta$ and decrease in $\gamma, \lambda$, and $\mu$. The sign of these elasticities is fairly intuitive as $\beta$ and $\gamma$ represent the valuation of the legal product and the illegal downloads, respectively, and $\mu$ the cost of producing one unit of the legal product. The value of $\lambda$ reflects the homogeneity of the consumers' preferences. Since downloading costs are much lower than production costs, when consumers are perfectly homogeneous, they would all use the P2P network, which obviously would be bad for the firm. Less intuitive is the fact that higher per unit cost $\mu$ increases consumer and total surplus. This is due to the fact that a higher production cost induces a higher price, which encourages consumers to download and consequently implies a gain in consumer surplus because of positive downloading externalities. As one would expect, this effect does not exist in the case before P2P was introduced, see Table 5 .

The signs of all elasticities with respect to $\beta$ are exactly the opposite of the signs of the corresponding elasticities with respect to $\gamma$. The intuition for $\beta$ and $\gamma$ having an opposite effect is quite obvious, with the exception of the negative effect of the valuation of the legal product on consumer surplus and total welfare. This effect can be explained by the fact that a higher valuation of the legal product induces consumers to switch from the P2P network to the store, thereby making it more costly to download for those downloaders who stay in the network as a consequence of the positive network externalities. Again, without the presence of P2P, $\beta$ naturally has a positive effect on the consumer surplus. The effects of $\beta$ and $\gamma$ on the price of the legal product are counterintuitive. A higher value of $\beta$ decreases $p$ while a higher value of $\gamma$ increases it. As we will explain in more detail later on, this is due to the price elasticity of demand for the legal product given the convex functional form of the cost of downloading.

The model outcomes are relatively inelastic with respect to the switching cost $\tau$, with the exception of profits $\pi$. A higher $\tau$ induces a decrease in all of the predicted market outcomes. In particular, switching costs have a negative effect on the prices and profits indicating that, for the calibrated values, our model predicts the long term incentive to attract new consumers ('investment effect') to dominate the short term incentive to harvest loyal consumers ('harvesting effect'). The literature on switching costs, see Cabral (2009) and Arie and Grieco (2014), has argued that the investment effect dominates when switching costs are low. Our calculations reveal that even when switching costs are substantial, the investment effect can still dominate. A higher switching cost forces the firm to charge a lower price, resulting in less profit. Nevertheless,

Table 6

Elasticities of steady state outcomes for variables in the rows with respect to the parameters in the columns; with P2P.

\begin{tabular}{llllllll}
\hline & $\beta$ & $\gamma$ & $\sigma$ & $\rho$ & $\tau$ & $\lambda$ & $\mu$ \\
\hline$p$ & -0.1525 & 0.0310 & -0.0018 & 0.0001 & -0.0932 & -0.2838 & 0.9228 \\
$s$ & 4.5938 & -4.5313 & 0.3125 & -0.0313 & -0.8750 & -4.8125 & -3.9688 \\
$n$ & -0.0207 & 0.5496 & -0.0363 & 0.0018 & -0.2377 & 0.2966 & 0.0179 \\
$\pi$ & 4.0326 & -4.3696 & 0.2935 & -0.0109 & -1.1413 & -5.8804 & -3.5109 \\
$c s$ & -0.0095 & 1.2219 & -0.0673 & 0.0025 & -0.2177 & -0.0476 & 0.0083 \\
$w$ & -0.0066 & 1.2177 & -0.0670 & 0.0024 & -0.2186 & -0.0521 & 0.0058 \\
\hline
\end{tabular}


also consumer surplus goes down, both for the situation with P2P as well as the situation without P2P. This is caused by the higher switching costs as incurred by the consumers in both cases and the higher downloading costs in the presence of P2P.

Consumers' taste heterogeneity is inversely related to the parameter $\lambda$ : a larger $\lambda$ implies less heterogeneity. Both tables reveal that an increase in $\lambda$ leads to a lower price. In the situation without P2P, a higher $\lambda$ makes it more difficult to attract consumers to the store and, despite the lower price, the effect on sales is negative. In the situation with P2P, these effects are reenforced by more consumers going to the network, resulting in even more negative effects on sales and profits in particular. Apparently, more heterogeneity complicates the formation of the P2P network and hence is beneficial to the firm. Both with and without P2P, welfare is negatively affected by a decrease in heterogeneity. Nevertheless, the effect of $\lambda$ on consumer surplus should be interpreted with caution, since the parameter $\lambda$ determines the size of the shocks to the consumers' utilities and, thus, has a direct effect on consumers surplus, in addition to other effects operating through the firm's pricing policy and the development of the network.

All elasticities with respect to the generic cost factor of downloading $\sigma$ have opposite signs as the elasticities with respect to the valuation of downloads $\gamma$. Higher $\sigma$ implies higher downloading costs for everyone, making P2P less attractive to consumers, similar to the effects of lower $\gamma$. However, the interpretation of $\sigma$ and $\gamma$ are quite different, which makes the implications different as well. The quality parameter $\gamma$ measures the value of a download to a consumer regardless of how the download is acquired. Thus, $\gamma$ only reflects the intrinsic quality of the downloaded copy, e.g. in the case of music, the sound quality. It does not reflect the fact that the copy has to be illegally downloaded and that it costs time and effort. That is what the cost factor $\sigma$ captures.

Enforcement of intellectual property rights relates to an increased value of $\sigma$. Table 6 shows that a higher $\sigma$ improves the profit of the firm and decreases consumer surplus and welfare. The total welfare suffers due to the lower size of the network $n$ and the sheer downloading costs that are incurred for those who do download. In other words, a social planner who aims at maximizing welfare should be careful in enforcing intellectual property rights in the context of P2P file sharing, considering the welfare enhancing effect of P2P shown in this crude yet vivid demonstration.

Furthermore, an increase in $\sigma$ does not lead to an increase in the price of the legal product as intuition may suggest, since high $\sigma$ harms the attractiveness of the P2P network against which the firm competes in price. In fact, if anything, the price decreases slightly in $\sigma$. This is attributable to the price elasticity of demand for the legal product, just as for the effects of $\beta$ and $\gamma$ on the price. To put it simply, when $\sigma$ increases, the P2P network becomes less attractive and there are a lot more potential consumers out there for the firm to win over, and hence it charges a slightly lower price to attract these switching consumers. Conversely, when $\sigma$ decreases, P2P becomes more attractive and a big chunk of consumers will go to the network, making the remaining consumers in the store relatively inelastic to prices, and hence the higher price. Ultimately, this pricing scheme is caused by the convex form of the downloading cost function with respect to the network size, $c(n)=\sigma /(\rho+n)$.

\section{Concluding remarks and managerial insights}

This paper uses a dynamic model to solve the optimal pricing policy for a firm that makes legal sales of music products and competes with the P2P file-sharing networks on the Internet.

An interesting point of this model is that we can observe the dynamics of network formation. We can also observe exactly how the firm sets its price conditional on its market share and the net- work size. While for given network size the price the firm sets is generally increasing in its market share, for a given market share the price behaves non-monotonically in the network size. Sometimes the firm sets the price very low in order to win vital market shares to fight against the P2P network, while at other times it accommodates the network by setting a high price to reap the profit from its own customers.

In the comparative static analysis of the model, one of our most important findings is that total welfare is negatively related to the generic cost factor of downloading. This result coincides with the findings by Rob and Waldfogel (2006) and Herings et al. (2010) in the sense that the existence of P2P actually enhances total welfare. This implies that by making file-sharing more difficult for the consumers, the government is effectively curbing the society from enjoying a high welfare level that P2P technology would generate. In our set-up the increase in total welfare is caused by the increase in consumer surplus being overwhelmingly larger in size than the decrease in the firm's profits. August and Tunca (2008) argues that increased enforcement of property rights can actually hurt vendor profits and Tunca and Wu (2013) presents evidence that a higher detection and prosecution rate for piracy can reduce the firm's profits due to strategic effects.

Other findings include an interesting pricing scheme of the firm in the sense that the steady state price decreases when the legal product becomes more attractive (higher valuation of the legal product or higher generic cost factor of downloading), and increases in the valuation of the competing product (higher valuation of the downloads and lower generic cost factor of downloading). Like in Herings et al. (2010), this is due to the convex functional form of the cost of downloads, which affects the price elasticity of demand of the legal product.

From the firm's perspective, we can answer the question "Accommodate it or fight it?" in the title as follows. On the one hand the optimal pricing policy shows that, ceteris paribus, the firm responds to a drop in sales by a drop in prices and sets lower prices when the network is relatively small, which indicates that the firm does fight. But, on the other hand, the firm cannot deter the evolvement of the P2P network without pricing sub-optimally, and hence will not fight till the bitter end, thereby ultimately accommodating the P2P network.

Instead of fighting against P2P networks, the music industry has also resorted to alternative business models. We already documented the rise of legal downloads in 2007. Meanwhile, subscription audio streaming services like Spotify and pure ad-supported video streaming services like Youtube and Vevo were introduced. Another development is the appearance of online radio platforms like Pandora. All these services contribute to the revenues of the record companies, but have by no means eliminated the huge problems posed by illegally obtained music. We believe that the extension of our model to incorporate these new developments would be a highly interesting direction for future research.

Although we have restricted ourselves to a model where the only shocks are in the utility functions of the consumers, our approach can easily be used to deal with other shocks. Examples would be shocks on the supply side like new production technologies, for instance the ones described in the previous paragraph, which could be treated by introducing stochastic shocks to the utility of the legal product $\beta$ or its per unit production costs $\mu$. Stochastic shocks may also affect the demand side, for instance when there are new legal developments, which would affect the generic cost factor $\sigma$ of downloading. We think that the introduction of these kinds of shocks would be an interesting direction for future research as well.

Finally, it must be clarified that the results of this paper by no means support the infringement of intellectual property rights or piracy in general. Although it is beyond the analysis of this 
paper, it is worth discussing whether indeed a new form of IPR mechanism (especially copyrights law) is needed in this fast-paced information-based society. Perhaps one that is much more relaxed with regard to the fair use of copyrighted materials. After all, the Web2.0 concept (community-based web environments such as Facebook, YouTube, and Myspace) encourages new content creation by the average public on such a massive scale that the traditional media could never have dreamed of. Yet, the existing copyright laws to a large extent stand in the way of such creative activities. Moreover, copyright laws are meant to encourage and protect creative incentives. When are creators hurt so much that their creative incentives are hindered by file-sharing? One should not forget that the content creators and the intellectual property rights owners are very often different entities - the former being the artists and the latter being the publishing firms. Damages incurred to IPR owners do not necessarily imply damages incurred to content creators, and it is the latter's creative incentives that matter. When analyzing the impact of movie broadcasts on DVD sales and Internet piracy, Smith and Telang (2009) suggest that creative artists can use product differentiation and market segmentation strategies to compete with freely available copies of their content. Is it not a good thing to reach an otherwise impossibly large audience even if that means one has to give away some music for free? In order to answer these questions, one has to consider the development of quantity, quality and variety of the music products over the years and search for signs of improvement or deterioration.

\section{Acknowledgment}

The authors thank the editor and the three anonymous reviewers for their valuable comments and suggestions.

\section{References}

Arie, G., \& Grieco, P. L. E. (2014). Who pays for switching costs? Quantitative Marketing and Economics, 12, 379-419.

August, T., \& Tunca, T. I. (2008). Let the pirates patch? An economic analysis of software security patch restrictions. Information Systems Research, 19, 48-70.

Bae, S. H., \& Choi, J. P. (2006). A model of piracy. Information Economics and Policy, $18,303-320$

Blackburn, D. (2004). On-line piracy and recorded music sales (pp. 1-60). Harvard University. Working paper

Blackwell, D. (1965). Discounted dynamic programming. The Annals of Mathematical Statistics, 36, 226-235.

Cabral, L. (2009). Small switching costs lead to lower prices. Journal of Marketing Research, 46, 449-451.

Chang, Y.-M., \& Walter, J. (2015). Digital piracy: Price-quality competition between legal firms and P2P network hosts. Information Economics and Policy, 31, 22-32.

Chen, J., Doraszelski, U., \& Harrington, J. E., Jr. (2009). Avoiding market dominance: Product compatibility in markets with network effects. RAND Journal of Economics, 40, 455-485.

Dewan, S., \& Ramaprasad, J. (2014). Social media, traditional media, and music sales. MIS Quarterly, 38, 101-121.

Doraszelski, U., \& Pakes, A. (2007). A framework for applied dynamic analysis in IO. In M. Armstrong, \& R. Porter (Eds.), Handbook of industrial organization: vol. 3 (pp. 1887-1966). Amsterdam: Elsevier.

Doraszelski, U., \& Satterthwaite, M. (2010). Computable Markov-perfect industry dynamics. RAND Journal of Economics, 41, 215-243.

Economides, N. (1996). The economics of networks. International Journal of Industrial Organization, 14, 673-699.

Gayer, A., \& Shy, O. (2003). Internet and peer-to-peer distributions in markets for digital products. Economics Letters, 81, 197-203.

Herings, P. J. J., Peeters, R., \& Yang, M. (2010). Competition against peer-to-peer networks. Information Economics and Policy, 22, 315-331.

Howard, R. A. (1960). Dynamic programming and Markov processes. Cambridge, Massachusetts: MIT Press.

IFPI (2008). IFPI digital music report 2008. (pp. 1-27), IFPI.

IFPI (2017). Global music report 2017 - Annual state of the industry. (pp. 1-44), IFPI.
Jenkins, M., Liu, P., Matzkin, R. L., \& McFadden, D. L. (2004). The browser war Econometric analysis of Markov perfect equilibrium in markets with network effects. Working paper, (pp. 1-72), Stanford University.

Johnson, W. R. (1985). The economics of copying. Journal of Political Economy, 93, 158-174.

Judd, K. L. (1998). Numerical methods in economics. Cambridge, Massachusetts: MIT Press.

Katz, M. L., \& Shapiro, C. (1985). Network externalities, competition, and compatibility. American Economic Review, 75, 424-440.

Katz, M. L., \& Shapiro, C. (1986). Technology adoption in the presence of network externalities. Journal of Political Economy, 94, 822-841.

Khouja, M., \& Smith, M. A. (2007). Optimal pricing for information goods with piracy and saturation effect. European Journal of Operational Research, 176, 482-497.

Khouja, M., \& Wang, Y. (2010). The impact of digital channel distribution on the experience goods industry. European Journal of Operational Research, 207, 481-491.

Lahiri, A., \& Dey, D. (2013). Effects of piracy on quality of information goods. Management Science, 59, 245-264.

Liebowitz, S. (2004). Will MP3 downloads annihilate the record industry? The evidence so far: vol.15. Advances in the study of entrepreneurship, innovation, and economic growth (pp. 229-260). Emerald Group Publishing Limited.

Liebowitz, S. (2006). File sharing: Creative destruction or just plain destruction. Journal of Law and Economics, 49, 1-28.

Luce, R. D. (1959). Individual choice behavior: A theoretical analysis. New York: Wiley.

Markovich, S. (2008). Snowball: A dynamic oligopoly model with indirect network effects. Journal of Economic Dynamics and Control, 32, 909-938.

Markovich, S., \& Moenius, J. (2009). Winning while losing: Competition dynamics in the presence of indirect network effects. International Journal of Industrial Organization, 27, 346-357.

MUSO (2017). Global music piracy insight report 2017.

Oberholzer-Gee, F., \& Strumpf, K. (2007). The effect of file sharing on record sales: An empirical analysis. Journal of Political Economy, 115, 1-42.

Peitz, M., \& Waelbroeck, P. (2004). The effect of internet piracy on music sales: Cross-section evidence. Review of Economic Research on Copyright Issues, 1, 71-79.

Peitz, M., \& Waelbroeck, P. (2005). An economist's guide to digital music. CESifo Economic Studies, 51, 359-428.

Peitz, M., \& Waelbroeck, P. (2006). Why the music industry may gain from free downloading - The role of sampling. International Journal of Industrial Organization, 24, 907-913.

Puterman, M. L. (1994). Markov decision processes, discrete stochastic dynamic programming. Hoboken, New Jersey: John Wiley and Sons.

Qian, Y. (2014). Counterfeiters: Foes or friends? How counterfeits affect sales by product quality tier. Management Science, 60, 2381-2400.

RIAA (2007). The CD: A better value than ever, an RIAA report prepared by the communications and strategic analysis department of the recording industry association of America.

RIAA (2009). 2008 year-end shipment statistics. 202-775-0101, RIAA.

Rob, R., \& Waldfogel, J. (2006). Piracy on the high C's: Music downloading, sales displacement, and social welfare in a sample of college students. Journal of Law and Economics, 49, 29-62.

Shcherbakov, O. (2009). Measuring consumer switching costs in the television industry. Unpublished manuscript. pp. 1-47.

Shum, M. (2004). Does advertising overcome brand loyalty? Evidence from the breakfast-cereals market? Journal of Economics and Management Strategy, 13, 241-272.

Shy, O. (2002). A quick-and-easy method for estimating switching costs. International Journal of Industrial Organization, 20, 71-87.

Siwek, S.E. The true cost of sound recording piracy to the U.S. economy, Policy report 188, 2007 Institute for Policy Innovation (pp. 1-28).

Smith, M. D., \& Telang, R. (2009). Competing with free: The impact of movie broadcasts on DVD sales and internet piracy. MIS Quarterly, 33, 321-338.

Sundararajan, A. (2004). Managing digital piracy: Pricing and protection. Information Systems Research, 15, 287-308.

Takeyama, L. N. (1994). The welfare implications of unauthorized reproduction of intellectual property in the presence of demand network externalities. Journal of Industrial Economics, 42, 155-166.

Train, K. (2003). Discrete choice methods with simulation. Cambridge: Cambridge University Press.

Tunca, T. I., \& Wu, Q. (2013). Fighting fire with fire: Commercial piracy and the role of file sharing on copyright protection policy for digital goods. Information Systems Research, 24, 436-453.

Waldfogel, J. (2010). Music file sharing and sales displacement in the iTunes era. Information Economics and Policy, 22, 306-314.

Waters, J. (2015). Welfare implications of piracy with dynamic pricing and heterogeneous consumers. European Journal of Operational Research, 240, 904-911.

Zentner, A. (2006). Measuring the effect of file sharing on music purchases. Journal of Law and Economics, 49, 63-88

Zhang, L. (2017). Intellectual property strategy and the long tail: Evidence from the recorded music industry. Management Science. (forthcoming). 